\title{
Sobre conocimiento y significado en el Essay de John Locke
}

\author{
GIANNINA BURLANDO \\ Pontificia Universidad Católica de Chile (Chile) \\ gburland@uc.cl
}

\begin{abstract}
Resumen
Al final del Libro II del An Essay Concerning Human Understanding, Locke manifiesta que «hay una relación tan íntima entre las ideas y las palabras [...] que es imposible hablar clara y distintamente de nuestro conocimiento, que consiste completamente en proposiciones, sin considerar, primero, la naturaleza, uso y significación del lenguaje». De varias y diversas maneras Locke insiste en la tesis que 'las palabras significan ideas'. En este ensayo me propongo: $1^{\circ}$ resumir la teoría general del lenguaje de Locke; $2^{\circ}$ revisar algunas objeciones regulares a esta teoría, y $3^{\circ}$ intentar una explicación de lo que Locke quiere decir cuando enuncia que 'las palabras significan ideas'. Con respecto a este punto mostraré, apoyando la interpretación de E. J. Ashworth, que en su tesis semántica Locke usa el vocablo 'significar' ('signifying') no del modo como es usado por los teóricos contemporáneos del siglo XX, sino en el sentido que algunos escolásticos usaron el término 'significare'.
\end{abstract}

Palabras claves: Locke; conocimiento; significado, escolásticos.

\section{John Locke's Essay on Knowledge and Meaning}

\begin{abstract}
At the very end of Book II of 'An Essay Concerning Human Understanding', Locke finds out «that there is so close a connexion between Ideas and Words [...] that it is impossible to speak clearly and distinctly of our Knowledge, which all consists in Propositions, without considering first the Nature, Use, and Signification of Language». In various and diverse ways Locke defends the thesis that 'Words signify Ideas'. My aim in this paper is first, to sum up Locke's general theory of Language; secondly, to revisit some regular objections concerning this theory, and thirdly, to intend an explanation of what Locke means when he points out that 'Words signify ideas'. In regard to this point, I shall hold up E. J. Ashworth's interpretation to show that Locke semantic thesis involves the use of the verb 'to signify' ('signifying') not in the manner that it is used by contemporary theorists of the twentieth century, but in the sense that some scholastics used the term 'significare'.
\end{abstract}

Key words: Locke; knowledge; meaning; scholastics.

Doctora en Filosofía. Profesora en el Instituto de Filosofía de la PUC. El presente estudio deriva resultados parciales del proyecto Fondceyt No 1110434. 
Mientras investiga acerca de la posibilidad del conocimiento humano, un tema central y dominante en la filosofía del siglo XVII, John Locke confiesa hallarse obligado por «la fuerza y manera de la significación de las palabras». Al final del Libro II del An Essay Concerning Human Understanding de 1690, Locke (1975) manifiesta que «hay una relación tan íntima entre las ideas y las palabras [...] que es imposible hablar clara y distintamente de nuestro conocimiento, que consiste completamente en proposiciones, sin considerar, primero, la naturaleza, uso y significación del lenguaje» (Locke, 1975: 401). De hecho, el propósito de los Libros II y III de esta obra es la descripción de dos tipos de signos, esto es, 'ideas' y 'palabras', que para Locke son: «los grandes instrumentos del conocimiento» (Locke, 1975: 721). Las ideas son signos de las cosas y las palabras son signos de las ideas. De varias y diversas maneras Locke insiste en la tesis que 'las palabras significan ideas'.

En este estudio me propongo: $1^{\circ}$ resumir la teoría general del lenguaje de Locke; $2^{\circ}$ revisar algunas objeciones regulares a esta teoría, y $3^{\circ}$ intentar una explicación de lo que Locke quiere decir cuando enuncia que 'las palabras significan ideas'. Con respecto a este punto mostraré, siguiendo la interpretación de E. J. Ashworth, que en su tesis semántica Locke usa el vocablo 'significar' ('signifying') no del modo como es usado por los teóricos contemporáneos del siglo $\mathrm{XX}^{1}$, sino en el sentido que algunos escolásticos usaron el término 'significare'. Sin embargo, y a pesar de su tesis semántica, dado que la teoría de las ideas de Locke exige un doble acuerdo, con ideas y con la existencia de cosas reales, no llega a salvar el escepticismo. O dicho de otro modo, intento derivar consecuencias de la doble función de las ideas en tanto entidades representativas de objetos físicos y en tanto contenidos lógicos de la mente-perceptiva.

\section{Teoría general del lenguaje según Locke}

Como ha notado Ashworth (1984), la posición epistemológica general de Locke se puede resumir en tres puntos centrales: 1) el uso del término 'idea'; 2) la tesis que todas las 'ideas complejas' están constituidas de 'ideas simples'; y 3) La tesis que el conocimiento es percepción (o intuición) del acuerdo y desacuerdo entre ideas.

\footnotetext{
1 Según Ashworth en la frase «teoría del significado», Locke no intenta ofrecer una teoría del significado del tipo expuesto por M. Dummet, por ejemplo, en "What is a Theory of Meaning" (1975: 97).
} 
Primero, 'idea' es el término que mejor sirve para (stand for) sustituir lo que sea el objeto del entendimiento cuando el hombre piensa. 'Lo qué sea' aquí quiere decir, sensaciones, conceptos, pensamientos, imágenes (phantasmatas), species ${ }^{2}$. Un phantasma es entendido como una imagen. La species incluye las especies sensibles o la sensación particular y la species inteligibles o lo que sea que es abstraído de la sensación particular. El uso que Locke hace del término 'idea' se extiende amplia e indiferentemente a sensibles inmediatos, sensaciones, recuerdos, nociones, imágenes y conceptos, pero Locke destaca por sobre todo su carácter de imagen. Las ideas, pues, son lo que sea que la mente emplea al pensar y también lo que sea el objeto del entendimiento que el hombre usa al pensar.

Segundo, la tesis de Locke que todas las ideas complejas están constituidas de ideas simples (por ej. ideas de 'poder', de 'existencia', de

2 Por su parte y en su epistemología Francisco Suárez considera que la simple aprehensión es también un tipo de «noción simple (notitia simplex) la cual es comunmente llamada aprehension simple en tanto tiene capacidad de verdad, puesto que es conocimiento, y de alguna manera en cuanto participa de la naturaleza del jucio es llamada simple aprehensión para notar que la potencia cognitiva forma en sí misma la similitude de la cosa, y de cierto modo, atrae la cosa hacia si [...]» (Suárez, 1962: VIII 4 6) (mis cursivas). Sin embargo, esta simple aprehensión es un tipo de imagen no-material que Suárez introduce en el proceso de cognición y describe igualmente como notitia de la cosa. La 'imago' aquí no es adquirida, sino lo que sea que es hecho por el intelecto (quatenus est aliquid factum ab intellectu). Su equivalente en términos de la epistemología cartesiana, es decir, "percibir» (percipi) refiere al acto interno de aprehensión directa que permite a la mente tener conocimiento de las verdades simples - tanto en lo que dice respecto a su propia naturaleza como en lo que dice respecto de la naturaleza de Dios y de los objetos de la matemática. Así como la visión externa funciona gracias a la luz del sol, también la percepción intelectual operada por la mente funciona gracias a una luz interior (luz natural e intuición).

3 Locke dedica el cap. XXI y parte del XXII del Libro II del Essay a explicar su idea de 'Poder'. Considera que la idea compleja de substancia contiene la idea de poder. Intenta alejarse del tipo de explicación teleológica aristotélica y se acerca a explicaciones mecanicistas, habla de la estructura física (micro cósmica) de las cosas. Así, dice «He that will examine his complex idea of gold will find several of the ideas that make it up to be only powers», y estos poderes son como agentes causales que producen cambios en otras cosas. Se está refiriendo, en parte, a la estructura mental, a los distintos tipos de poderes de la mente. Ofrece una clasificación ontológica al afirmar que «Los Poderes son Relaciones» (Locke, 1975: 243) (agrego cursiva); pero, usa una definición naturalista de la idea de Poder, es decir, «La fuente [mental/corporal] de la cual todas las acciones proceden [...]» (Locke, 1975: 294). Resultará de interés averiguar las implicaciones de estos postulados, o si funcionan como base, ya física o ya ontológica, de sus doctrinas morales y políticas. Por ejemplo, en cuanto a su teoría moral en el Essay llega a una conclusión en la que relaciona la voluntariedad y la libertad humana, escribe, el «Power to suspend volition explains responsibility for ill choice. These things, duly weighed, will give us, as I think, a clear view into the state of human liberty. Liberty, it is plain, consists in a power to do, or not to do; to do, or forbear doing, as we will. This cannot 
'unidad') está ligada a la tesis que todas las ideas simples llegan a nosotros, son adquiridas desde la experiencia (es decir, no se originan en nosotros, no son innatas) sean estas desde las sensaciones, que están ante la mente cuando percibimos o sentimos, o desde las reflexiones donde las ideas representan las operaciones de la propia mente ${ }^{4}$.

En tercer lugar, la tesis de Locke que el conocimiento es la percepción de la conexión y del acuerdo o desacuerdo y repugnancia de

be denied. But this seeming to comprehend only the actions of a man consecutive to volition» (Locke, 1975: 270). En este análisis, Locke continua derivando sus ideas sobre 'Liberty', 'Greatest Good', 'Uneasiness as first step to Happiness', o 'considering Consequences of Accions', etc. En cuanto a sus propósitos políticos, Locke defiende que «la ley de la naturaleza sería [...] en vano, si no hubiese nadie [...] [que] tuviera el poder para ejecutar la ley» (Locke, 1960: 312). A su vez, este tipo de poder (es decir, el que se ejerce en relación a otro semejante) y «ejecuta» esa ley, debe establecerse por consentimiento y contrato, sólo así será legítimo poder político.

4 Hume está básicamente de acuerdo con Locke en negar que la mente contenga ideas innatas, ambos filósofos empiristas efectivamente piensan que la mente adquiere todo su material desde la experiencia. Sin embargo, Hume postula que «los objetos de la mente» no son ideas sin más, sino percepciones, las cuales a su vez son de dos tipos: impresiones e ideas. Para Hume la fuente de cualquier fenómeno mental no es el pensamiento o el razonamiento, sino la percepción, la sensación y la emoción. La distinción entre las percepciones: impresiones e ideas, reside en que las percepciones que entran con más fuerza y vivides a la conciencia son impresiones, vale decir, sensaciones, pasiones y emociones, mientras que las ideas son débiles, descoloridas imágenes de estas impresiones. Así pues, lo que Locke llama ideas, Hume llama percepciones. Esta distinción, piensa Hume, sirve para restaurar el sentido originario del término idea que, según él, Locke había distorsionado (Hume, 1978: 1ss). Entre otras cosas, las perspectivas de Locke, y particularmente las observaciones de Hume fundan una tradición en psicología filosófica contemporánea la cual ha defendido que impresiones tales como pasiones y/o emociones son sensaciones, o al menos, experiencias de un tipo especial que incluyen sensaciones. Así, en textos de psicología de principios del siglo XX se encuentran explicaciones tales como las de Scout quien, por cierto, distingue entre emociones disposicionales (como por ejemplo el gusto y el disgusto, el amor y el odio) y las emociones en general, pero sostiene que la emoción misma en la cual se actualiza una emoción disposicional es «siempre un estado actual de conciencia» que además de la sensación y de la tendencia connata «incluye también tipos específicos de sensación que no pueden reducirse a elementos más simples» (Gustafson, 1964: 78). Entre otros, W. James, igualmente cree que una emoción es un sentimiento (feeling), aunque identifica el sentimiento con sensaciones somáticas. En un famoso pasaje de sus Principles of Psychology nos advierte que su teoría sostiene que «los cambios corpóreos siguen directamente la percepción de un hecho excitante, y que nuestros sentimientos de los mismos cambios tal como ocurren ES la emoción» (James, 1890: 449), en este pasaje es James quien destaca las mayúsculas. Russell, también adherente de esta tradición empirista, sostiene que las emociones incluyen movimientos corpóreos. Nos dice que «una emoción (es) un cierto tipo de proceso [...] Los ingredientes de la emoción son solo sensaciones, imágenes y movimientos corpóreos sucediéndose entre ellos de acuerdo a cierto patrón» (Russell, 2004: 284). 
cualquiera de nuestras ideas (Locke, 1975: 402-403), literalmente quiere decir que bajo ninguna circunstancia Locke acepta que la mente o el agente perceptor pueda estar directamente relacionado con algún objeto que no sea una idea o la misma mente. Locke repite esta tesis más de una vez, escribe por ejemplo: «el hombre no tiene noción de nada... excepto por la Idea que él tiene de [la cosa] en su mente» (Locke, 1975: 393-394). $Y$ añade: «la mente no conoce cosas inmediatamente, sino solo por la intervención de las Ideas que tiene de ellas [las cosas]» (Locke, 1975: 421). De hecho, Locke nunca tuvo la intención de negar que en muchas ocasiones nosotros tenemos conocimiento del mundo externo y de que podemos estar ciertos de que tenemos tal conocimiento. Por lo demás, tanto su creencia en el papel intermediario de las ideas y su creencia de que podemos conocer el mundo externo son relevantes para su principal tesis semántica, vale decir, para su creencia que 'las palabras significan ideas.' Veremos, en seguida, que tanto el papel intermediario que Locke atribuye a las ideas como su tesis sobre las palabras están relacionadas a fuentes escolásticas.

\section{Objeciones a la epistemología de Locke}

En cuanto al tema de la extensión y limitaciones del conocimiento humano, en la interpretación de R. Aaron (1971: 224), se destaca que para Locke nuestro conocimiento es percepción o intuición lo cual efectivamente es un tema central en la epistemología de Locke. Sin embargo, si comparamos la noción de 'intuición' de Locke con una teoría epistemológica anterior, como la de Descartes, encontramos, efectivamente, una significativa distancia entre ambas, puesto que: «Con intuición [Descartes dice] no me refiero al mundo oscilante de los sentidos, o al juicio engañador de la imaginación, que reúne las cosas, remedándolas, sino más bien a la concepción de una mente clara y atenta, tan fácil y distinta que no puede restar espacio a la duda acerca de aquello que entendemos» (Reglas, agrego cursivas). Por lo cual el objeto de lo que Descartes llama 'intuición' es un objeto puro, y no sensible ${ }^{5}$. Mientras

\footnotetext{
5 Para Descartes, que sigue la tradición de san Agustín (De trinitate XII, xv 24) para describir la cognición mental, afirma que hay dos especies de conocimiento intuitivo (intuitus, derivada de la palabra latina intueri, cuyo significado es simplemente ver o inspeccionar), uno que se encuentra en nosotros en tanto hombres y es puramente intelectual, y el lumen natural o la intuito de la mente la cual solo retiene aquello en que se debe confiar. Según Descartes la mente cuando se libera de la interferencia de los estímulos sensoriales tiene el poder innato de «ver», o aprehender directamente las verdades que Dios implantó en ella. Dice: «Con intuición no me refiero al mundo
} 
que para Locke con 'intuición' entiende que aunque la mente «ve» inmediatamente una conexión necesaria, esta es una relación entre ciertos datos dados (givens) en la sensación o reflexión o entre ideas complejas siempre derivadas de los datos del sentido. Según Locke la intuición consiste en la percepción de una relación entre ideas uiltimamente derivadas sin excepción de la sensación o de la reflexión. El objeto de la intuición nunca es completamente intelectual y puramente no sensible. En este sentido Locke difiere considerablemente de Descartes. Por lo que podemos decir que Locke acepta el intuicionismo pero únicamente como parte de su perspectiva empirista de la percepción.

Locke comienza definiendo el conocimiento como 'la percepción de la conexión y acuerdo de cualquiera de nuestras ideas'. Estas ideas son derivadas de la sensación y de la reflexión, así pues, su definición de conocimiento es consistente con la teoría empirista del origen de las ideas. Sin embargo, el significado de la frase 'conexión y acuerdo' nunca queda claro. Los ejemplos del 'acuerdo' en el Libro IV del Essay son todas sobre 'proposiciones'. Si se asume, como hace ver Aaron, que Locke tiene en mente proposiciones, su análisis del tipo de acuerdo será un análisis de proposiciones. Así, percibir un acuerdo puede significar percibir una relación entre proposiciones o puede significar percibir una relación de implicación entre proposiciones, y este conocimiento inevitablemente ya no es de objetos reales, sino de relaciones entre ideas.

Otra crítica de Aaron apunta a que Locke comienza asumiendo, primero, que el conocimiento debe ser absolutamente cierto, y segundo, que debe ser acerca de lo real, queriendo decir, acerca de existencias físicas o mentales. Pero en este sentido del término, la conclusión que se deriva es que para la mente humana es posible conocer muy poco. Porque el objeto inmediato de nuestra mente es la idea. Si luego, se sostiene que

oscilante de los sentidos, o al juicio engañador de la imaginación, que reúne las cosas, remedándolas, sino más bien a la concepción de una mente clara y atenta, tan fácil y distinta que no puede restar espacio a la duda acerca de aquello que entendemos. Alternativamente lo que termina por significar lo mismo, intuición es la concepción de una mente clara y atenta, que avanza solamente por la luz de la razón. Así cualquiera puede intuir que existe, que piensa, que un triángulo se limita solo por tres lados y una esfera por una superficie única, y así lo demás» (Cottingham, Stoothoff \& Murdoch, 1988: 14). Pero inseparable de la explicación cartesiana de la intuición es la noción platónico-agustiniana de que la mente es iluminada por la «luz de la razón» o lux rationis de la que habla en las Reglas y en su Correspondencia en general. En estos textos se hace explícito que para Descartes el conocimiento intuitivo es una iluminación de la mente por la cual ella ve en la luz de Dios las cosas que le gusta descubrir a través de una impresión directa de la claridad divina sobre nuestro intelecto que en esto no es considerado como agente, sino solo como receptora de los rayos de la divinidad. (Belgiogioso, 2005). 
conocemos el objeto físico real, lo conocemos mediatamente a través de la idea. Pero nuestras ideas son complejas, y para conocer el objeto externo completamente, incluso de esta manera mediata, tendremos que conocer que la idea compleja en nuestra mente lo representa completa y adecuadamente. Pero precisamente esto nunca lo sabemos. Locke mismo escribe: «El que construye forma una idea que consiste en una colección de todas esas ideas simples que están en cualquier cosa, tiene conocimiento perfecto de esa cosa, pero sobre esto debo abstenerme hasta que encuentre una instancia» (Locke, 1975: 119. 165). Efectivamente, tal instancia puede no encontrarse nunca. Porque para conocer que la idea sea adecuada tendríamos que ir más allá de la idea, necesitaríamos conocer directamente el objeto externo, y esto, ex bypothesis, es imposible. Luego, de esta primera interpretación del conocimiento en Locke se derivan consecuencias indeseables.

Cabe pues una nueva interpretación que emerge gradualmente, y, en la que Locke encontraría alivio. En esta interpretación Locke sigue manteniendo que el conocimiento es cierto y que se distingue de la opinión y la mera creencia, sin embargo, no es conocimiento de objetos, sino de relaciones entre ideas, como ya mencionamos. Los primeros ejemplos que Locke ofrece de este tipo de conocimiento son de 'proposiciones idénticas', tales como: 'el blanco no es negro', 'el todo es más grande que la parte', etc. Obviamente estas son instancias de conocimiento, pero desafortunadamente afirmarlas ya es tratar con palabras que, además, no resultan informativas. Lo cual también lleva lejos del conocimiento de objetos reales y, entonces, el escepticismo parece igualmente inevitable.

En el Libro IV del Essay Locke da comienzo a su nuevo planteamiento: 'que el conocimiento es percepción de la relación entre ideas'. La primera limitación del conocimiento es que 'podemos tener conocimiento no más allá de nuestras ideas.' Y dado que las ideas son dadas directamente ya sea en la sensación o en la reflexión, esto querría decir que no podemos saber completamente lo que hay más allá de nuestra experiencia sensible y reflexiva. Al determinar la extensión del conocimiento humano Locke llega a la siguiente posición: que estamos limitados, en primer lugar, por la misma experiencia: Cuando no tenemos ideas, no podemos tener conocimiento. E incluso, cuando la experiencia nos provee de ideas, no siempre podemos intuir relaciones necesarias entre ellas. Siempre podemos conocer que una idea es (en sí misma) y que no es otra. También podemos conocer ciertas conexiones necesarias entre ideas cuando a través de la abstracción las liberamos de sus referencias externas y tratamos con ellas en tanto ideas que son sus propios arquetipos. Ahora bien, si se trata particularmente de la 
matemática, no hay límite para la obtención del conocimiento. Pero si consideramos las ideas en tanto imágenes o representaciones del mundo externo, la mente puede conocer pocas, y tampoco relaciones necesarias entre ellas. Por tanto, no es posible la ciencia del mundo natural en sentido estricto, tampoco sobre la naturaleza humana. En estos ámbitos, la mente humana debe a fortiori descansar en la experiencia, y de ésta no podemos obtener un sistema exacto de conocimiento necesario. Entonces ¿podemos conocer con certeza que algo existe? Dada la definición de conocimiento de Locke ¿cómo podemos conocer qué cosas existen? (las cosas que no son ideas, ni relación entre ideas). Así, según esta interpretación, el Libro IV del Essay es un esfuerzo desesperado pero sin éxito para salvar el abismo entre idea y cosa. Nuestro conocimiento es real, si las ideas conforman lo real, lo cual conocemos mediatamente a través de ideas. Pero ¿de qué manera podemos comprobar su acuerdo o conformidad? O como Locke mismo pregunta «Cómo deberá, la mente cuando percibe nada más que sus propias ideas, conocer que ellas acuerdan con las cosas en sí mismas?». Parece, pues, que un examen de correspondencia nunca puede ser aplicado ${ }^{6}$. Nos queda entonces averiguar, qué quiere decir Locke al enunciar que: 'Las palabras significan ideas'.

\section{Las palabras significan ideas}

La versión directa de esta tesis es «que las palabras, en cuanto son usadas por los hombres, propia e inmediatamente, pueden significar nada más que ideas que están en la mente del hablante» (Locke, 1975: 406) Partiendo de este pasaje nos gustaría explorar, primero, ¿qué tipo de palabras significan ideas? Y en segundo lugar, ¿isi Locke usa el término 'significar' ('signifying') como sinónimo de 'meaning' o, más bien, como un equivalente del término escolástico 'significare? (En este último caso se podría entender lo que Locke dice sobre la significación de los términos generales, y cómo es que nuestras ideas conforman tanto con las ideas de otros hombres como con el mundo externo). Podemos conjeturar, siguiendo a Ashworth, que la creencia de Locke en el papel intermediario de las ideas y su tesis que las palabras significan ideas en la mente del

\footnotetext{
6 La definición del Libro IV, 1 parece aplicarse solo al conocimiento de proposiciones universales. Para Locke hay dos tipos de conocimiento en el mundo, general y particular, basados en dos principios diferentes, esto es, ideas verdaderas y materia de hechos o historia (Locke, 1975: 618). En este sentido Locke limita cierto conocimiento al conocimiento de lo general, mientras que el conocimiento de lo particular se caracteriza sólo como probable.
} 
hablante está relacionada a fuentes escolásticas. Los escolásticos aún enseñaban en Oxford y Cambridge en la época de Locke. Él pudo, por ejemplo, haberse familiarizado con la Logica de Martin Smiglecius (c.1564-1618) ${ }^{7}$, varias veces reimpresa en Oxford, la cual con ecos del coetáneo conceptualismo suareciano explica que:

El conocimiento es inmediatamente del objeto tal como está en la mente, pero de la cosa fuera de la mente solo como está representada mediante lo que está en la mente, como parecerá más claro en la siguiente cuestión. Porque ser conocido en el sentido formal es ser conocido en la mente, y ser formado en la mente. De aquí, si las cosas existen fuera de la mente o si no existen, ellas son conocidas bajo el aspecto de un objeto, porque ellos existen formalmente en la mente, y como ellos están en la mente, son conocidos. Ser objetivamente es, estar en la mente, no fuera de la mente, porque en tanto las cosas están fuera de la mente, ellas no son conocidas, excepto como representadas por la mente. De aquí, el objeto del conocimiento es la cosa tal como está en la mente, en virtud de la cual la cosa que está fuera del intelecto es llamada objeto. Ese es inmediato, este último; ese intrínseco, este extrínseco; ese esencial, sin el cual no puede haber conocimiento; este no esencial y sin cuya existencia actual puede haber conocimiento, porque si existe o no existe [la cosa], hay conocimiento, en virtud del objeto mental ${ }^{8}$.

$7 \quad$ Martin Smiglesius se une a la Sociedad de Jesús en 1581; fue profesor de filosofía y teología en Vilna; reconocido por su erudita y popular obra Logica (1618), varias veces reimpresa en Oxford, donde fue usada como manual de estudio.

8 En la traducción inglesa de Ashworth, cito: «Knowledge is immediately of the object as it is in the mind, but of the thing outside the mind only as it is represented by that which is in the mind, as will appear more (clearly) in the following question. For, to be known in the formal sense is to be known in the mind, and to be formed in the mind. Whence, whether things exist outside the mind or whether they do not exist, they are known under the guise of an object, because they exist formally in the mind, and as they are in the mind, so they are known. To be objectively, is to be in the mind, not outside the mind, for insofar as things are outside the mind, they are not known, except as represented by the mind. Whence the object of knowledge is the thing as it is in the mind, by virtue of which the thing outside the intellect is called the object. That is inmediate, this ultimate; that intrinsic, this extrinsic; that essential, without which there can be no knowledge, this non-essential and without whose actual existence there can be knowledge -for whether it exists or not, there is knowledge, by virtue of the mental object» (Ashworth, 1988: 160-161). En cambio en una solución del tipo de realismo semántico como la de Sto. Tomás de Aquino, cito: «debe decirse que la concepción del intelecto es algo medio entre el intelecto y la cosa entendida, porque mediante ella, la operación del intelecto alcanza la cosa: y por eso la concepción del intelecto no solo es aquello que es entendido, sino también aquello mediante lo cual la cosa se entiende, de modo que, así, tanto la cosa misma como la concepción del intelecto puede decirse que son lo entendido. $\mathrm{Y}$, de manera semejante, tanto la cosa que es dicha como el verbo mismo puede decirse que son lo dicho, como también es claro en el verbo exterior, porque el 
Por cierto la explicación de cómo conocemos el mundo y la de la naturaleza de los objetos lógicos de Smiglecius pertenece a un desarrollo tardío de la concepción medieval de lenguaje?. Ahora bien, el estudio del lenguaje por parte de los lógicos medievales en general presenta una variedad de teorías de cuya complejidad solo puedo mencionar aquí algunos aspectos y detallar solo uno ellos. En tal teoría se pueden enumerar los siguientes componentes: (i) Una teoría de los términos: incluye una división de ellos en abstractos y concretos, comunes y singulares, connotativos y absolutos, categoremáticos y sincategoremáticos ${ }^{10}$; (ii) Una teoría de la suposición (suppositio en latín), la cual en parte es una teoría de la referencia y en parte una teoría de la cuantificación $^{11}$. Detalladamente tratada por diversos lógicos medievales,

nombre mismo es dicho y también la cosa significada por el nombre es dicha mediante el nombre mismo» (Aquino, 2004: 86).

9 En efecto, para los medievales el lenguaje era algo institucional, es decir, algo instituido por los hombres de manera convencional, arbitraria, impuesta. Esta institucionalidad tenía que ver, primero, con la relación que tiene el lenguaje con otros aspectos de la realidad humana y social. Así entienden que el lenguaje se refiere al pensamiento, es expresión del pensamiento, de tal manera que aquello que pensamos toma cuerpo y es comunicable precisamente a través del lenguaje. Sin embargo, el pensamiento en cuanto tal no es arbitrario, es pensamiento de algo y ese algo es lo que llamamos realidad, mundo, estado de cosas, u objetos públicos. La realidad no es convencional, no es inventada por el ser humano. Si bien la relación entre lenguaje y pensamiento es convencional, no lo es la relación entre el pensamiento y la realidad. Por otra parte, el lenguaje - las lenguas - cambia con el tiempo. Para explicar este cambio que surgía con las costumbres, los usos y sus variaciones, los medievales distinguían entre tipos de imposición. Pero la naturaleza convencional del lenguaje hay que considerarla más bien como un presupuesto que como una teoría del origen histórico del lenguaje; presupone, entre otras cosas, cierta preeminencia del pensamiento con respecto al lenguaje, pues si no hay pensamiento previo, no habría lenguaje (Campos, 2002: 306).

10 Los primeros, según P. Hispano, significan algo por sí mismos (por ejemplo, un nombre $y$ un verbo, ambos constituyen un enunciado simple. Los términos sincategoremáticos sólo significan cuando acompañan a los categoremáticos. Por esto se llaman 'significativos' o 'predicativos' y significan su cuantificación, en el caso de los nombres aliguid o aliqua. Los sincategorémáticos son «con-significativos» como las constantes lógicas, por ello significan aliqualiter o de alguna manera» (Beuchot, 1987: 41). El compromiso ontológico de estos puede descubrirse investigando si son absolutos o connotativos y luego determinando si su connotación es externa. Trazos firmes de esta teoría de los términos se encuentra en la Parte I de la Summa Logicae de Ockham, publicada en Oxford, 1675, ampliamente discutida por su contemporáneo parisino, Jean Buridan, en Libro VII de sus Quaestiones in Libros metaphysicam aristotelis.

11 Parte interesante de la teoría de la suposición, como destaca Campos, es la teoría de la ampliación (o ampliatio en latín), la cual aborda los usos de una palabra cuando su referencia se extiende; hoy se explica esta función recurriendo a la 'intensión' y 'extensión' de las palabras. 
entre quienes se destacan Doctores de Oxford, Viena y París, tales como Ockham, Burley, Alberto de Sajonia, o Buridan, Autrecourt y Smiglesius, el jesuita polaco mencionado ${ }^{12}$. (iii) Una teoría de la definición ${ }^{13}$. (iv) Una teoría del lenguaje mental ${ }^{14}$, (cuyo ímpetu se debió a san Agustín, De Trinitate 15, y a los Comentarios Segundos sobre el De Interpretatione de Aristóteles de Boecio ${ }^{15}$. Pero desde el siglo XIV, con Ockham y sus discípulos, las discusiones sobre el lenguaje mental se multiplicaron. Se puso atención a qué tipo de estructura gramatical debía exhibir un tal lenguaje mental, y cómo se podría dar cuenta de la unidad de las proposiciones gramaticales. Todavía en el siglo XVII tanto en Oxford como en Lyon o Coimbra se encuentran trazos del debate sobre el lenguaje mental. Finalmente, como corolario de la teoría del lenguaje mental se desarrolló (v) la teoría de la significación. Una teoría de la significación medieval (significatio en latín) no tiene que ver exactamente con una teoría del significado del siglo XX tal como la defienden Russell o M. Dummett (1975), es decir, con una detallada especificación del significado o referencia o denotación de todas las palabras y oraciones del lenguaje ${ }^{16}$. En verdad,

12 Cabe destacar que la suposición trata de los usos de las palabras. Tanto las palabras como las oraciones se pueden referir al lenguaje mismo, a conceptos o entidades mentales y sus contenidos y a cosas e individuos concretos. Llamaron estos niveles de referencia suposición material, simple y personal, respectivamente. Así abordan lo que hoy se titula 'metalenguaje' i.e., lo que hace referencia al lenguaje mismo y sus propiedades.

13 Suárez, De Anima, 1978: 59ss. Según los textos medievales existían dos tipos de definición: La definitio quid nominis o definición nominal, la cual explicaba la significación de una palabra; y la definitio quid rei o definición real, la cual en palabras de Philip Du Trieu, jesuita holandés, era una «definición que explica la naturaleza de la cosa significada por un nombre». Este tipo de definición, según F. Suárez, fue también llamada 'esencial' y se aplicaba solo a las substancias.

14 La cual remonta al tratado De Interpretatione 16a 3 de Aristóteles. Allí sostiene que las palabras habladas son signos de afecciones en la mente.

15 A partir de Boecio se asumió que habían tres tipos de lenguaje: el hablado, el escrito y el mental. El lenguaje hablado y escrito tienen significados impuestos, mientras que el lenguaje mental, se presuponía común a todos los hombres, por tanto, debía tener significaciones naturales. Los términos mentales eran significativos en virtud de su propia naturaleza. Ockham (1980: 193-197. 251-253) concibió el lenguaje mental como lógicamente anterior y preeminente al lenguaje instituido, y las oraciones habladas eran significativas solo si estaban subordinadas a las oraciones mentales.

16 Como expone J. C. García, dentro de los límites demarcados por la teoría contemporánea, "el significado de toda expresión del lenguaje es comprendido, básicamente, desde una perspectiva orientada objetualmente, es decir, el significado es comprendido y teoréticamente asimilado sobre la base de una relación directa o indirecta con objetos, modelados a partir del patrón suministrado por los objetos espacio-temporales, o sea, entes dotados de existencia independiente y, por lo mismo, identificables mediante criterios perfectamente definidos y explícitos. El significado de 
para una parte importante de lógicos medievales el pensamiento en cuanto que entidad mental —es decir, en cuanto que especies, ideas, o conceptos- era literalmente el significado (significatum) de las palabras ${ }^{17}$. Esto quiere decir que es un error suponer que hay significados de cualquier tipo que puedan ser identificados, y que el verbo 'significar' sea un término de relación, o bien que la frase 'El significado de «P»' sea una frase referente ${ }^{18}$. El vocabulario semántico de los medievales de hecho admitía palabras como 'signo', 'significar' y 'significación', pero ellas eran entendidas como cualidades psicológico-causales y en general no como referentes ${ }^{19}$. Este hecho tiene dos importantes consecuencias para el debate sobre el lenguaje mental. Primero, refuerza el énfasis en los estados mentales en tanto opuestos a entidades abstractas tales como el significado; y en segundo lugar, muestra que la significatio no era una noción de referencia tout court. En el Siglo XIII, el Maestro portugués Pedro Hispano, en sus Summulae Logicae, había definido 'significación' como «la representación de algo (rei) por medio de una expresión según convención» $»^{20}$. Todavía la definición de 'significare' usada por Pier D'Ailly

una expresión del lenguaje o es el objeto referido mismo, sea este concreto o abstracto, o es alguna otra entidad que entremedia en la relación sostenida por la expresión en cuestión y el objeto referido, o sea, dicha entidad torna indirecta la relación de referencia. Esta entidad puede ser concebida como poseyendo un carácter abstracto, como puede verificarse, por ejemplo, en el caso de Frege y Husserl, o uno mental, como en el caso de los empiristas ingleses. Ahora bien, esta entidad, al ser concebida, por los autores recién nombrados, como una entidad epistémica y ontológicamente independiente del lenguaje, se presenta como yuxtapuesta al objeto que constituye el referente de la expresión lingüística. Dicha yuxtaposición trae consigo la tentación irresistible de asimilar la mentada entidad como un objeto. Los efectos de ceder a esta tentación pueden apreciarse en Frege mismo» (García, 2004-2005: 59-80).

17 Beuchot, 1987; Ashworth, 1984; Kretzmann, 1982.

18 Para los lógicos medievales, si asumiéramos que: (a) el verbo 'significare' en oraciones como 'La palabra «P» significa $\chi$ ' es un término relacionador, y que (b) la frase ' $\mathrm{El}$ significado de «P» es una frase referente, entonces una teoría de la significación sería una que explica a qué tipo de entidad están relacionadas las palabras y cuáles asignan una denotación a las frases referentes en cuestión (Ashworth, 1980).

19 El origen de esta alteración parece estar en el hecho que en los manuscritos medievales la palabra significare era frecuentemente abreviada y luego erróneamente leída como signare. Además los mismos autores medievales algunas veces parecen dudar sobre qué término prefieren (Kretzmann, 1982).

20 Para P. Hispano y más para Guillermo de Sherwood (compatriota de R. Bacon, escribe el tratado de Insolubilia en 1240 ¿?) la significación de una expresión es algo abstracto. Así mismo, el modo de entender (modus intelligendi) eso abstracto estuvo sujeta a diversas interpretaciones (Beuchot, 1987). En cuanto a la mayoría de los comentaristas de Frege están de acuerdo en que él no define nunca la noción de sentido. Para Frege el sentido no es algo mental, ni algo físico, sino un objeto abstracto. Se puede decir, sin embargo, que como matemático Frege no se preocupaba de la 
en su Conceptus et insolubilia (París: 1495), era: «Representar algo o algunas cosas o de alguna manera al poder cognitivo» ${ }^{21}$. Por lo cual el significatum de un término no es tanto su referente, sino lo que hace conocido, expresa o presenta al pensamiento del hablante y solo secundariamente a lo que ése esté haciendo referencia ${ }^{22}$.

Otro importante aspecto de la teoría del significado era determinar si las palabras significan primaria e inmediatamente cosas o conceptos. Martin Smiglecius responde que las palabras significan primariamente cosas y significan conceptos solo en un sentido extendido. Mientras que otros lógicos post-medievales como Du Trieu, Sanderson (1756) y Burgersdijck (1684-1714, Profesor en Lieden) responden que los conceptos son aún más centrales en el proceso significativo, y que las palabras son usadas para referir a cosas más que a conceptos, pero describen la situación diciendo que las palabras significan conceptos inmediatamente mientras que significan cosas solo mediatamente a través de los conceptos intermediarios. Burgersdijck escribe explícitamente que: «las pronunciaciones articuladas significan conceptos de la mente primariamente, esto es, inmediatamente, porque ellas también significan cosas, pero mediante los conceptos» (Ashworth, 1984: 64). Y es esta posición la que coincide con la tesis semántica de Locke, para quien: 'las palabras en su primaria e inmediata significación, están por (stand for) nada, excepto ideas en la mente de quien las usa'. Según Ashworth, Locke adopta la posición de Du Trieu y de Burgersdijck en el orden de prioridad entre conceptos y cosas, porque ese orden calza muy bien con su propia doctrina del lugar de las ideas en el conocimiento, particularmente con el conocimiento del mundo externo. Las Ideas son

naturaleza de estos entes, sólo aprecia las estructuras. En esto su actitud parece pragmática en vez de platónica, porque el sentido cumple una función teórica en su modelo: la de estar en cierta relación lógica con ciertos objetos y en tanto proposición es condición abstracta -de- verdad.

21 Así pues, una palabra podía significar al menos cuatro cosas: (1) a ella misma, (2) al locutor, (3) al concepto del locutor y (4) al objeto referido por el locutor.

22 Para algunos medievales 'pensamiento', 'concepto' o 'proposición' no es exactamente equivalente al 'acto de la representación mental', sino más bien al contenido de ella. Igual que el sentido de Frege, es lo que pensamos cuando pensamos una expresión. Para Frege el sentido o modo de presentación del objeto es idéntico al pensamiento que él llama proposición. Sentido, pensamiento y proposición para Frege son un tipo especial de objeto, uno lógico. El problema es que pensar un objeto, según Frege, es capturar (grasp) un sentido que presenta ese objeto. Esto quiere decir que el modelo fregueano de intencionalidad parece conducir a un regreso ad infinitum. Porque la mente captaría sentidos que son objetos que a su vez presentan objetos de otro tipo. Si para Frege el sentido es la «ruta» hacia la referencia de las expresiones, para algunos medievales la significatio es también una vía para reconocer la suppositio o referencia. 
objetos inmediatos en el lenguaje del mismo modo en que lo son en el conocimiento.

Locke no escribe específicamente sobre las cuestiones concernientes al lenguaje mental, pero de algún modo las toma como lugar común filosófico. Así, por ejemplo, en el Libro IV habla de 'proposiciones mentales'. Según Ch. Landersmann (1976: 26), una proposición mental para Locke es el acto mental por el cual la mente percibe un estado de cosas, y las ideas, en tanto componentes de los actos mentales, son signos de los estados de cosas. De nuevo, cuando define la verdad, Locke destaca que es difícil considerar la Verdad del Pensamiento y la Verdad de las Palabras separadas una de la otra, afirma: 'al tratar sobre las Proposiciones mentales es inevitable hacer uso de palabras: y luego, las instancias dadas de las Proposiciones mentales inmediatamente dejan de ser puramente mentales y pasan a ser verbales.' (Locke, 1975: 574). Luego, es evidente que Locke sostiene una teoría de la significación y del lenguaje mental. De hecho, otros conocedores de Locke tales como: N. Kretzmann, Landersman, D. Odegard y J. W. Yolton, se suman a Ashworth para destacar al menos tres argumentos que apoyan la tesis semántica de Locke. Tales argumentos son que:

1. 'Era necesario que el Hombre debía hallar algunos signos externos sensibles, mediante los cuales aquellas ideas invisibles [...] pudieran hacerse conocidas a otros' (Locke, 1975: 405).

2. 'Siendo las palabras Signos voluntarios, no pueden ser Signos voluntariamente impuestos por él a las cosas que no conoce' (Locke, 1975: 405).

3. Usar palabras sin 'una conexión constante entre el sonido y la idea' es hablar como loro (Locke, 1975: 408).

Lo notable de estos argumentos de Locke extraídos de su capítulo sobre «El Significado de las Palabras» es que todos ellos estaban ya enunciadas en la Lógica de Smiglecius, aunque en su propio planteamiento Smiglecius las rechaza. En palabras suyas formula que:

1. Las palabras fueron dadas al hombre para hacer conocida su mente, la cual está escondida.

2. Las palabras solo pueden significar cosas mediante conceptos (ratio) por los cuales son concebidas las cosas.

3. Un hablante que no concibe nada, no significa nada, como lo hace un loro.

En cuanto a la pregunta ¿si Locke usa el término 'significar' ('signifying') como sinónimo de 'meaning' o más bien como un equivalente del término escolástico 'significare? nos parece ya haber mostrado que no solo para los lógicos post medievales, sino también para Locke las 
anteriores son afirmaciones estándares en que se basa la tesis de que 'las palabras significan inmediatamente ideas'.

En cuanto a la primera pregunta que levantamos al comienzo: ¿qué tipo de palabras significan ideas para Locke? debemos notar que Locke nunca afirma que todas las palabras significan ideas. Según N. Kretzmann (1968) y las sugerencias de E. J. Ashworth (1984) ${ }^{23}$, para Locke algunas palabras como por ej. 'nada', o 'ignorancia' significan la ausencia de ideas (III 14 ), y las partículas o términos sincategoremáticos tales como: 'si', 'ninguno', 'todos', significan algunas conexiones que la mente da a las ideas o proposiciones o de unas con otras (Locke, 1975: 471). En realidad, el único tipo de palabras discutido por Locke en el Libro III son sustantivos y adjetivos o nombres. Los nombres, según Locke, significan ideas. De este análisis, parece un error inferir que Locke usara el verbo 'to mean' como término relacional de frases tales como 'el significado de' o como una 'frase referente' entendida en el contexto de las teorías del significado del siglo XX como ha defendido W. P. Alston (1964). Dar el significado de una palabra no es nombrar algún ítem. Aunque hay pasajes en el Essay en los que Locke equipara ideas con significados (Locke, 1975: 386. 412. 422), pero Locke no desarrolla una 'teoría del significado' (del tipo que le adscribe Alston). La palabra latina 'significare' no es equivalente a la palabra inglesa 'meaning', porque, además:

(i) El uso estándar de la palabra 'meaning' en la época de Locke era el de sinónimo de 'signification'; (ii) Locke usa 'meaning' raramente y de un modo casual; (iii) por el contrario, él repite constantemente las palabras 'signos', 'significar' y 'significación' dándoles un uso técnico o terminológico del mismo modo en que se lo dieron los teóricos escolásticos del lenguaje. Es por esta razón que en el capítulo sobre 'El significado de las palabras' escribe: «Pero cualquiera sea la consecuencia del uso diferente que hace cualquier hombre de las palabras, sea de su significado general o del sentido particular de la persona a quien las dirija, esto es cierto, su significación, en su uso de ellas, está limitado a sus ideas, y ellas pueden ser signos de nada más» (Locke, 1975: 408).

El uso de Locke del término 'significar' tiene mucho más sentido filosófico si uno lo interpreta en el contexto de la teoría escolástica del lenguaje que si uno lo trata de acomodar en el contexto de las teorías del significado del siglo XX.

Se puede afirmar efectivamente que Locke tiene una "teoría del significado» pero si ésta se interpreta en el sentido de que Locke se preocupó de dar un criterio para el uso del lenguaje, y que él priorizó en

23 Otros artículos relevantes de la autora son: Ashworth, 1981 y 1982. 
términos de ideas y discurso mental, para lo cual efectivamente ofrece diversas indicaciones prácticas ${ }^{24}$. Por ejemplo, el principal consejo metódico de Locke es que podemos evitar las ideas confusas, y resulta que la confusión en relación a las ideas se puede definir en relación al uso del lenguaje. El remedio para la confusión es asegurar que nuestras ideas sean precisas y determinadas ofreciendo definiciones (Locke, 1975: 552), es decir, enumerando las ideas simples (Locke, 1975: 412). Cuando esto es imposible, nos aconseja usar las palabras consistentemente, es decir, manteniéndolas ligadas a una idea determinada (Locke, 1975: 366. 493. 552). El punto principal para Locke es que debemos asegurarnos de que nuestro uso del lenguaje sea consistente con el uso de los demás, ya que las palabras 'no son posesión privada del hombre, sino la medida común del comercio, la transacción y la comunicación' (Locke, 1975: 470. 514).

$\mathrm{Y}$ estas recomendaciones prácticas dependen de la explicación que Locke nos da acerca de la doble conformidad que las ideas significadas por las palabras deben poseer:

Por una parte nuestras ideas deben acordar o conformarse a las ideas de otros usuarios de lenguaje ${ }^{25}$, y

Por otra parte, nuestras ideas deben acordar o conformarse a la existencia real de las cosas.

\section{Notas Conclusivas}

De la descripción que hace Locke de la 'conformidad' o 'acuerdo' de nuestras ideas a otras ideas de otros usuarios de lenguaje se puede concluir que su teoría del lenguaje es novedosa, porque enfatiza el lugar que ocupan las ideas en el proceso significativo y esto puede interpretarse como un énfasis en la importancia que adquieren conceptos, creencias y percepciones de los hablantes en el proceso de la comunicación. Además, Locke tuvo una genuina conciencia de que en el

24 Por ejemplo, el principal consejo metódico de Locke es que podemos evitar las ideas confusas, pero resulta que la confusión en relación a las ideas se puede definir en relación al uso del lenguaje. El remedio para la confusión es asegurar que nuestras ideas sean precisas y determinadas ofreciendo definiciones (Locke, 1975: 412).

25 Sean ideas en tanto nombres de ideas simples, por ejemplo, 'blanco'; sean modos mixtos, por ejemplo, 'justicia', 'triángulo'; o sean ideas complejas, por ejemplo, 'hombre', 'substancia' y 'oro'. Al considerar la conformidad entre nuestras ideas de substancias y los objetos externos, Locke habla de nuestras ideas de substancia como si ellas fueran imágenes o semejanzas de las cosas (Locke, 1975: 145) y de nuestras ideas de substancia escribe: 'a veces ellas son solamente diseñadas para ser pictures y representaciones en la mente de las cosas que existen' (Locke, 1975: 378). 
uso del lenguaje hay algo que es público. Me parece que quedó claro que su teoría del lenguaje, también posee una teoría semántica, y no solo un conjunto de observaciones; esta corresponde a su teoría del lenguaje mental y de la significación adoptada desde los escolásticos, aunque de modo truncado. Porque las ideas del lenguaje mental para Locke, a diferencia de los escolásticos y de Descartes, no tienen un status lógico o mental, no son proles mentis, ni quatenus est aliquid factum ab intellectu, no tienen una realidad formal, por el contrario, son adquiridas, abstraídas o unidas desde ideas simples obtenidas en la experiencia; tampoco tienen una realidad objetiva, no son entidades intencionales, acerca-del-mundoreal, no están dirigidas a los objetos; no obedecen a conexiones necesarias entre causas y efectos de la naturaleza. Al requerir de las ideas un acuerdo con la realidad de las cosas, Locke intenta salir del círculo de nuestras ideas, puesto que una relación entre una idea y una existencia real no es una relación entre ideas. Sin embargo, en este punto, Locke enfrentó un problema mayor cuya consecuencia es el escepticismo, ya que si la mente solo conoce sus propios estados ¿cómo puede saber con qué existentes reales, si es que hay alguno, sus ideas concuerdan y están conectadas? Por cierto, los escolásticos buscaron resolver este problema con la distinción formal/objetiva del concepto, y Descartes, además de adoptar tal distinción en la realidad de la idea, apelando a la bondad divina, quien se supone garantizar la existencia de un mundo real correspondiente a nuestras ideas innatas ${ }^{26}$. Locke no encontró una mejor solución, más bien ignoró toda esta dificultad y asumió que nuestras ideas, de hecho, nos dan información del mundo real.

\section{REFERENCIAS}

-Aaron, R. I. (1971). John Locke. Oxford: Clarendon Press. -Adam, Ch., Tannery, P. (Eds.) (1964-1976). Oewures de Descartes. Paris: Vrin.

26 Según Descartes la idea puede considerarse en tanto que posee un contenido explícito, que es aquello que inmediatamente advertimos en ella, y también puede considerarse en tanto que tiene un contenido implícito; es decir un contenido que no es advertido de manera inmediata, el cual, sin embargo, sí puede ser conocido de manera mediata siempre y cuando usemos nuestra facultad de percepción al examinar con atención el contenido explícito de la idea. Además, la idea considerada de esta manera, es la idea considerada en tanto que verdaderamente representa o en tanto que conforma con algo. Esto se debe a que la idea considerada de esta manera es la idea considerada como una entidad lógicamente ideal; es decir como constituida de manera tal que consistentemente obedece ciertos principios lógicos normativos característicos de nuestra facultad de percepción, que es la facultad que tenemos de representar correctamente las cosas. 
-Alston, W. P. (1964). Philosophy of Language. New York: Englewood Cliffs.

-Aquino, T. (2004). Sobre la Verdad: Las Cuestiones Disputadas Sobre la Verdad. Madrid: Biblioteca Nueva.

-Ashworth, E. J. (1981). Mental Language and the Unity of Propositions. Franciscan Studies, (41), 61-69.

-Ashworth, E. J. (1982). The Structure of Mental Language: some Problems discussed by early sixteenth century logicians. Vivarium, 20 (1), 59-83.

-Ashworth, E. J. (1984). Locke on Language. Canadian Journal of Philosophy, XIV (1), 45-73.

-Ashworth, E. J. (1988). Traditional Logic. En Ch. B. Schmitt \& Q. Skinner (Eds.), The Cambridge History of Renaissance Philosopby (págs. 143-172). Cambridge: Cambridge University Press.

-Belgiogioso, G. (Ed.) (2005). Descartes Tutte le Lettere 1619-1650. Milano: Bompiani Il Pensiero Occidentale.

-Beuchot, M. (1987). Aspectos bistóricos de la semiótica y la filosofía del lenguaje. México: Instituto de Investigaciones Filológicas.

-Campos Benítez, J. M. (2002). Una teoría medieval del lenguaje. En G. Burlando (Ed.), Enciclopedia de Filosofía Iberoamericana (págs. 305-317). Madrid: Trotta.

-Cottingham, J., Stoothoff, R. \& Murdoch, D. (Eds.) (1988). The Philosophical Writings of Descartes (J. Cottingham, R. Stoothoff and D. Murdoch, Trads. de vol. I y II). Cambridge: Cambridge University Press.

-Descartes, R. (1987). Discurso del método. (A. Quintás, Trad.). Madrid: Alfaguara.

-Dummet, M. (1975). What is a Theory of Meaning? En S. Guttenplan (Ed.) Mind and Language (págs. 97-138). Oxford, Clarendon Press.

-García, J. C. (2004-2005). La teoría del significado del Tractatus: Elementos para una interpretación modal de la filosofía del primer Wittgenstein. Seminarios de Filosofia (17-18), 59-80.

-Gustafson, D. F. (1964). Essays in Philosophical Psycology. New York: Anchor Books.

-Hume, D. (1978). A Treatise on Human Nature (L. A. Selby-Bigge, Ed.). Oxford: Oxford University Press.

-James, W. (1890). The Principles of Psychology. New York: Holt.

-Kretzmann, N. (1968). The Main Thesis of Locke's semantic Theory. The Philosophy Review, 77 (2), 175- 196.

-Kretzmann, N., Kenny, A. \& Pinborg, J. (Eds.) (1982). The Cambridge History of Later Medieval Philosophy. Cambridge: Cambridge University Press.

-Landersman, Ch. (1976). Locke's Theory of Meaning. Journal of the History of Philosophy, 14 (1), 23-35.

-Locke, J. (1975). An Essay Concerning Human Understanding (P. H. Nidditch, Ed.). Oxford: Oxford University Press.

-Locke, J. (1960). Two Treatises of Government (P. Laslett, Introduction and Notes, Rev. Ed.). Cambridge: Cambridge University Press. 
-Ockham, W. (1980). Quodlibeta septem. En J. C. Wey (Ed.), Opera theologica9. New York: University of St. Bonaventure.

-Russell, B. (2004). The Analysis of Mind. New York: Cosimo Classics.

-Stout, G. F. (1938). A Manual of Psycology. London: University Tutorial Press.

-Suárez, F. (1962). Disputaciones Metafísicas. (S. Rábade et al., Ed. y Trad.) Madrid: Gredos.

-Suárez, F. (1971-1991). Commentaria una cum Questionibus in Libros Aristotelis de Anima (Vol. I-III, S. Castellote, Ed.) Madrid: Fundación Xavier Zubiri.

Sumario: 1. Teoría general del lenguaje según Locke; 2. Objeciones a la epistemología de Locke; 3. Las palabras significan ideas; Notas Conclusivas; Referencias. 